\title{
Pirei na Cenna: outra forma de construção de identidade cultural
}

\author{
Pirei na Cenna: another way of building \\ cultural identity
}

Cíntia Sanmartin Fernandes

Doutora em Sociologia Política (UFSC/SC) e pós-doutora em Comunicação pela UFRJ e PUCSP. Atualmente é professora adjunta do Programa de Pós-graduação em Comunicação UERJ e pesquisadora do grupo de pesquisa Comuniçação, Arte e Cidade (CAC). .

Patrícia da Glória

Mestre em Comunicação pelo Programa de pós-graduação em Comunicação da Universidade do Estado do Rio de Janeiro (PPGCOM/UERJ), onde integra o grupo de pesquisa Comunicação, Arte e Cidade (CAC). .

Resumo: O presente artigo analisa, a partir do caminho das Epistemologias do Sul, a potencialidade do Grupo de Teatro do Oprimido Pirei na Cenna ser identificado como uma das vozes que vem emergindo no atual contexto pós-colonial. Igualmente, busca-se observar se, por meio do espetáculo teatral, o grupo consegue estabelecer um espaço de comunicação intercultural (tradução) com a sociedade ao expor as consequências do estigma da loucura e ao abrir espaço para construir uma narrativa própria de identidade cultural dentro e fora do palco.

Palavras-chave: Teatro; Comunicação; Interculturalidade

Abstract: This article analyzes, from the path of South Epistemologies, if the Group Theatre of the Oppressed Pirei na Cenna can be identified as one of the voices that is emerging in today's post-colonial context. Also, it tries to observe if, through theatrical performances, the group manages to establish an area of intercultural communication (translation) to society by exposing the consequences of the stigma of madness and open space to build its own narrative of cultural identity within and off stage.

Keywords: Theatre, Communication, Interculturality. 
Era uma vez...

Me amarram, me aplicam

me sufocam

num quarto trancado

Socorro

Sou um cara normal

asfixiado

(Hamilton, Maurício e Alexandre M., do grupo Harmonia Enlouquece)

... um grupo de loucos fazendo teatro. Dá para apostar que quem lê essa frase, escrita assim sem contexto, rapidamente faz referência à excentricidade ou extravagância dos artistas, e que dificilmente alguém a entenderia em sua forma literal. Caso o fizesse, imaginaria algo muito rudimentar, sem qualidade. Tal comportamento parece ter menos a ver com o reduzido número de grupos teatrais com essa característica do que com o que é expresso pelo sanitarista Paulo Amarante, pesquisador do Laboratório de Estudos e Pesquisas em Saúde Mental e Atenção Psicossocial (Laps/Ensp/Fiocruz):

O resultado prático da psiquiatria clássica, ao considerar a loucura doença, erro absoluto, distúrbio da razão, perda do juízo, incapacidade civil, irresponsabilidade social e jurídica, foi criar para o louco um lugar de exclusão, um lugar zero de trocas sociais (ROTELLI, 1990), cuja expressão mais radical é o manicômio (AMARANTE, 2009, p.5).

Essas ideias de exclusão e incapacidade do 'louco' não ficaram restritas aos tratamentos terapêuticos e muito menos aos manicômios. Pelo contrário, elas também tinham vida do lado de fora das instituiçóes psiquiátricas e funcionavam como marcadores e diferenciadores, uma vez que, como destaca Michel Foucault, "nossa sociedade não quer reconhecer-se no doente que ela persegue ou que encerra; no instante mesmo em que ela diagnostica a doença, exclui o doente" (FOUCAULT, 1975, p. 51). Com isso, ficava mais fácil continuar no jogo dicotômico da construção da identidade, a partir da lógica do 'eu sou em oposição ao que eu não sou'.

Aos confinados em instituiçóes psiquiátricas, esse jogo de construção identitária lhes era proibido. Junto ao prontuário e uniforme - que retirava os últimos traços aparentes de individualidade - recebiam uma nova identidade, onde se encontrava definido tudo o que passaria a ser sua vida, sem espaço para dúvida ou abertura de possibilidades. $\mathrm{O}$ trabalho do médico era por demais conclusivo. Machado de Assis refinadamente (e ironicamente) sintetizou o funcionamento dessa lógica científica com seu personagem Simão Bacamarte, no conto O Alienista:

Suponho o espírito humano uma vasta concha, o meu fim, Sr. Soares, é ver se posso extrair a pérola, que é a razão; por outros termos, demarquemos definitivamente 
os limites da razão e da loucura. A razão é o perfeito equilíbrio de todas as faculdades; fora daí insânia, insânia e só insânia. (ASSIS, 1994)

Dessa forma, tachados como incapazes e produtores apenas de sandices, os 'loucos' tiveram suas identidades resumidas ao diagnóstico e passaram a ter suas histórias contadas e recontadas pelos outros. Histórias estas que acabaram por fazer parte da herança cultural da sociedade brasileira e mundial.

O que, talvez, a certeza da ciência não pôde prever ou que, seguramente, não conseguiu conter, foi a existência de rachaduras nos muros dos hospícios, aberturas nos diagnósticos e potencialidades que a doença não extinguia. E não são poucos os exemplos que podem confirmar isso: Lima Barreto, John Nash, Bispo do Rosário e Vaslav Nijinsk. Cada um, com suas particularidades, escreveu sua própria história e contribuiu para provocar profundos arranhóes no estigma da loucura.

Assim como estes casos, muitas outras iniciativas vêm pondo em xeque, ao longo dos anos, o estatuto da ciência que padroniza, náo negocia e determina o que é a 'verdade'. São vozes que querem escrever suas próprias histórias e se levantam contra Epistemologias que reconhecem apenas determinados tipos de conhecimentos e póe no obscurantismo tudo o mais.

O presente trabalho pretende se ater em outros saberes, que não apenas o científico e que o diálogo entre eles pode ser muito bem-vindo e produtivo. Para tal, tomará como objeto de pesquisa o Grupo de Teatro do Oprimido Pirei na Cenna, que funciona no Hospital Psiquiátrico de Jurujuba (Niterói $-\mathrm{RJ})$.

A escolha por este grupo de teatro foi motivada pelo fato de que ele, já na origem, é um grupo heterogêneo, formado por usuários dos serviços de saúde mental e familiares, profissionais da saúde e integrantes do Centro de Teatro do Oprimido (CTO); e que, desde sua criação, em 1997, tem o intuito de apresentar histórias a partir do ponto de vista do usuário e provocar com isso uma transformação na imagem que a sociedade tem da loucura. Para isso, utiliza o teatro como ferramenta de comunicação e mediaçáo com a sociedade.

A proposta deste artigo é verificar, a partir do caminho das Epistemologias do Sul, apontado pelo sociólogo português Boaventura de Sousa Santos, se o Pirei na Cenna cumpre esse papel de denunciar que teorias do conhecimento podem ser utilizadas para supressão de muitas formas de saber e se o grupo consegue, por meio do processo de traduçáo, proposto por Homi Bhabha, estabelecer um espaço de comunicação intercultural com a sociedade, ao expor as consequências do estigma da loucura e ao abrir espaço para construir uma narrativa própria de identidade cultural dentro e fora do palco. Para isso, o presente trabalho fará análise das peças "É melhor prevenir do que remédio dar" e "Doidinhos para trabalhar" do Grupo de Teatro do Oprimido Pirei na Cenna. 


\section{O imaginário social}

Ao longo da história, os indivíduos que de alguma maneira não se ajustavam à ordem vigente ou ao instituído socialmente, foram ocupando diferentes papéis, passando por clarividentes, excêntricos, marginais e até incapazes sociais, em virtude das mudanças que ocorriam na sociedade. Como observado por Michel Foucault:

Um fato tornou-se, há muito tempo, o lugar comum da sociologia e da patologia mental: a doença só tem realidade e valor de doença no interior de uma cultura que a reconhece como tal. A doente de Janet que tinha visóes e apresentava estigmas, teria sido, sob outras condiçóes, uma mística visionária e taumaturga (FOUCAULT, 1975, p. 49).

Uma explicação para esse processo de caracterização tanto do indivíduo quanto das práticas sociais como um todo, pode ser encontrada na construçáo do imaginário (1) social, como indica a historiadora Sandra Jatahy Pesavento:

O imaginário é histórico e datado, ou seja, em cada época os homens constroem representaçôes para conferir sentido ao real. Essa construção de sentido é ampla, uma vez que se expressa por palavras/discursos/sons, por imagens, coisas, materialidade e por práticas, ritos, performances. O imaginário comporta crenças, mitos, ideologias, conceitos, valores, é construtor de identidades e exclusôes, hierarquiza, divide, aponta semelhanças e diferenças no social (PESAVENTO, 2003, p. 43).

As marcaçóes de diferenças e semelhanças sociais que são geradas ocorrem a partir de uma relação de forças, como indica Stuart Hall: "As identidades, portanto, são construídas no interior de poder (FOUCAULT, 1986). Toda identidade é fundada sobre uma exclusão e, nesse sentido, é 'um efeito de poder" (HALL, 2008, p.81), e provoca implicaçôes concretas na sociedade, como aponta Sandra Jatahy Pesavento:

Aquele que tem o poder simbólico de dizer e fazer crer sobre o mundo tem o controle da vida social e expressa a supremacia conquistada em uma relação histórica de forças. Implica que esse grupo vai impor a sua maneira de dar a ver o mundo, de estabelecer classificaçóes e divisóes, de propor valores e normas, que orientam o gosto e a percepçáo, que definem limites e autorizam os comportamentos e os papéis sociais (PESAVENTO, 2003, p. 41-42).

E assim, em um dado momento da História, uma determinada Epistemologia (teoria do conhecimento), nesse caso a ciência moderna, ganhou o cabo-de-guerra e fez com que os loucos fossem excluídos e, subtraídos da identidade que os diferenciaria de qualquer outra pessoa, foi-lhes imposta a condição de serem apenas mais um no grupo dos diagnosticados com transtornos mentais. É como se, ao dizer que 'fulano é louco', isso já representar tudo sobre ele, até porque, como ressalta Sousa Santos:

(...) a epistemologia que conferiu à ciência a exclusividade do conhecimento válido traduziu-se num vasto aparato institucional - universidades, centros de investigação, sistema de peritos, pareceres técnicos - e foi ele que tornou mais difícil ou mesmo impossível o diálogo entre a ciência e os outros saberes" (SOUSA SANTOS, 2009, p.11). 
Esse foi o pacote difundido na sociedade, que não tinha motivos para contestar já que, como destaca Sousa Santos, a "consagração da ciência moderna nestes últimos quatrocentos anos naturalizou a explicação do real, a ponto de não o podermos conceber senão nos termos por ela propostos” (SOUSA SANTOS, 2008, p.84).

Os termos propostos poderiam construir as bases do imaginário social, mas representavam muito pouco (ou quase nada) do que de fato acontecia na sociedade e com seus indivíduos. O sistema cultural é dinâmico e composto por toda sorte de indivíduos, grupos e conhecimentos, para além do que é eleito pelo discurso hegemônico, como aponta Homi Bhabha:

A partir do lugar do 'enquanto isso', onde a homogeneidade cultural e o anonimato democrático articulam a comunidade nacional, emerge uma voz do povo mais instantânea e subalterna, discursos de minoria que falam em um espaço intermediário e entre tempos e lugares" (BHABHA, 1998, p.223).

As visóes de mundo impostas pelos produtores de poder simbólico vencedores, difundidas por um discurso hegemônico, não conseguem conter o transbordamento da pluralidade das práticas sociais e do próprio conceito de identidade, que rompem as barreiras do imaginário social vigente e se posicionam de maneira, senão contrária, diferente a ele. Afinal, como destaca Sanmartin:

(...) a socialidade não é construída apenas com normas e regras institucionais formais, mas também por uma 'centralidade subterrânea' informal, que assegura o compartilhar e o viver social. Assim, o mundo vivido mantém um espaço de liberdade institucional, mantém um espaço de criação, de profanação do instituído (SANMARTIN, 2009, p.94-95).

Por mais aprisionadas ou relegadas à invisibilidade que possam ser, as forças destoantes à Epistemologia adotada não desaparecem e, muitas vezes, são frutos de contradiçóes dos próprios discursos oficiais. Contudo, o que mais interessa a este trabalho é identificar se o choque com as normas e padróes estabelecidos provoca algum tipo de mudança na construção da identidade cultural do indivíduo e no imaginário social da sociedade.

\section{No fantástico mundo da pluralidade}

Não é de hoje que diversos movimentos têm 'gritado' bem alto que não se enquadram ou se satisfazem com o oferecido pelas identidades culturais, com tendências à uniformização e homogeneização, e muito menos com a maneira com que a sociedade se apresenta. Para citar alguns: Geração Beat (década de 50), Hippie, Nova Esquerda, Movimento Feminista, Poder Negro (década de 60), Reforma Psiquiátrica e Tropicalismo (década de 70).

Ao começar a ressoar e ganhar volume outras vozes, que o falso estado de equilíbrio e controle dos discursos dominantes tenta abafar, o que sobressai é a ferida aberta e não recuperável de que, como revela Bhabha:

As grandes narrativas conectivas do capitalismo e da classe dirigem os mecanismos de reprodução social, mas não fornecem, em si próprios, uma estrutura fundamental para aqueles modos de identificação cultural e afeto político que se formam em torno de questóes de sexualidade, rap, feminismo, a mundo de refugiados ou 
migrantes ou o destino social fatal da AIDS” (BHABHA, 1998, p.25).

Enquanto determinada Epistemologia tenta dar contar de tudo e homogeneizar as experiências sociais, as lacunas deixadas no processo vão sendo ocupadas por uma pluralidade de práticas e conhecimentos, que continuam existindo e se intercambiando. Este trabalho parte do princípio de que esta ocupação gera um choque que póe em evidência a mácula do processo oficial de construção de identidades e do imaginário social; e que exige legitimidade para suas questóes, que até então não compunham o interesse dos discursos hegemônicos.

A estas vozes, que são compostas em sua raiz por toda uma gama de outros conhecimentos tornados invisíveis, que Sousa Santos nomeia de Epistemologias do Sul, conceito que também adotamos e que representa, nas palavras do sociólogo:

el reclamo de nuevos procesos de producción, de valorización de conocimientos válidos, científicos y no científicos, y de nuevas relaciones entre diferentes tipos de conocimiento, a partir de las prácticas de las clases y grupos sociales que han sufrido, de manera sistemática, destrucción, opresión y discriminación causadas por el capitalismo, el colonialismo y todas las naturalizaciones de la desigualdad en las que se han desdoblado; el valor de cambio, la propiedad individual de la tierra, el sacrificio de la madre tierra, el racismo, al sexismo, el individualismo, lo material por encima de lo espiritual y todos los demás monocultivos de la mente y de la sociedad - económicos, políticos y culturales - que intentan bloquear la imaginación emancipadora y sacrificar las alternativas. En este sentido, son un conjunto de epistemologías, no una sola, que parte de esta premisa, y de un Sur que no es geográfico, sino metafórico: el Sur antiimperial (SOUSA SANTOS, 2011, P.16).

Desta forma, movimentos como os da Luta Antimanicomial e Reforma Psiquiátrica são fundamentais para deixar à mostra a tensão pulsante existente na sociedade e demonstrar que também há espaço para difundir seus saberes e há maneiras de exercer força para a construção de novas identidades culturais, como indica Bhabha:

A própria possibilidade de contestação cultural, a habilidade de mudar a base de conhecimentos, ou de engajar-se na 'guerra de posição', demarca o estabelecimento de novas formas de sentido e estratégias de identificação. As designaçóes da diferença cultural interpelam formas de identidade que, devido à sua implicação contínua em outros sistemas simbólicos, são sempre 'incompletas' ou abertas à tradução cultural (BHABHA, 1998, p. 228).

Isto é, no mesmo palco social onde são encenadas as identidades culturais representadas como algo imutável, encontram-se as tantas outras que fogem do laço da homogeneizaçáo, indicando a incompletude de todas. É justamente no encontro destes 'círculos abertos', que são as identidades, que é mediado o processo de comunicação cultural, a tradução (2), onde esta não significa assimilação de um pelo outro, mas sim potência de formação de algo novo, uma vez que as identidades passam a se construir e reconstruir na 'relação com'. Nada disso é garantia de consenso ou de se trabalhar para alcançar 'a verdadeira identidade' que vai finalmente dar conta de tudo. O grande saldo positivo da tradução é compreender a incompletude das identidades e dialogar com elas, num processo contínuo. 
Assim, as vozes das minorias e seus discursos chegam também ao primeiro plano das discussóes e com isso conseguem espaço para transformar a identidade que não lhes cabe em uma onde elas vão se reconhecendo. As minorias se tornam escritores de suas próprias histórias.

\section{Contando outra história}

Ao invés de somente assistir a peças encenadas por atores profissionais, sair da plateia e ganhar os palcos assumindo que qualquer pessoa pode ser ator, uma vez que "ser Ser Humano é ser artista" (BOAL, 2008, p.184). Esse pode ser destacado como um dos grandes diferenciais presentes nas produçôes do Teatro do Oprimido (TO) (3), através de sua metodologia conhecida por Estética do Oprimido, criada por Augusto Boal, em 1970. A ideia parece simples, mas é bastante transformadora: ao sair da condição de espectador e assumir um lugar no palco, a pessoa também se torna protagonista de sua vida.

Por isso, nos grupos e oficinas que utilizam a metodologia do TO, todas as etapas de produção de um esquete ou peça são construídas, num processo de negociação, com as pessoas que fazem parte do grupo e o tema da história a ser contada se origina sempre de uma situação realmente vivida pelos participantes. Segundo Boal, no Teatro do Oprimido, não só se mostra a realidade como ela é, mas como pode vir a ser! "Para isto, vivemos: para vir a ser, não para termos sido!” (BOAL, 2008, p.133).

Esse caminho também é percorrido pelos usuários dos serviços de saúde mental que experimentam o Teatro do Oprimido. Ao utilizar a metodologia do TO, eles se apropriam não somente da produção técnica, mas da construção de uma narrativa própria, que de fato se assemelha com eles. Isso porque a prática do TO contribui para pôr em xeque saberes cristalizados e preconceitos aceitos como condição de verdade, como pode ser observado nas palavras de Augusto Boal: "Não vamos jamais pedir que façam uma coisa que obviamente não podem fazer, mas não vamos, por outro lado, pressupor que são incapazes sem antes termos experimentado" (BOAL, 2008, p.236).

$\mathrm{Na}$ medida em que os usuários vão dominando a técnica e ocupando seu lugar no palco, isso acaba por fortalecer neles a percepção de suas potencialidades e de que não precisam ocupar os papéis de excluídos e incapazes, oriundos da herança cultural e presentes ainda hoje no imaginário social. Isso porque o trabalho que o Teatro do Oprimido desenvolve com os usuários é baseado na saúde e não na doença em si, pois se tem a compreensão de que diagnóstico não é identidade e, muito menos, passaporte para fora do contexto e práticas sociais e do exercício da cidadania. Por isso, de acordo com Boal, no desenvolvimento da metodologia do TO:

\footnotetext{
Não devemos limitar a escolha dos temas àqueles relacionados à saúde mental [...] Usuários, doentes, pacientes, enfermos, portadores de deficiências etc. são cidadãos com os mesmos direitos básicos de qualquer Cidadão, e alguns específicos da sua condição. Os usuários têm problemas de transporte, alimentação, desemprego, racismo, sexismo, corrupção etc. (BOAL, 2008, p.238).
}

Nesse sentido, o trabalho do TO segue a mesma proposta que integra as 
Epistemologias do Sul de emancipação social de Sousa Santos, o qual representa: "toda a acção que visa desnaturalizar a opressão (mostrar que ela, além de injusta, não é nem necessária nem irreversível) e concebê-la com as proporçôes em que pode ser combatida com os recursos à mão" (SOUSA SANTOS, 2008, p.30).

E a metodologia do Teatro do Oprimido é uma excelente escolha, pois foi criada com a proposta de, como esclarece Sérgio Mamberti, na apresentação do livro A Estética do Oprimido: "intervir concretamente na realidade, fazer emergir consciências e transformar simples consumidores em cidadãos capazes de produzir cultura - o que acarreta consequências individuais e sociais" (BOAL, 2008, p.9).

\section{Ultrapassando muros reais e simbólicos}

Assim trabalha o Grupo de Teatro do Oprimido Pirei na Cenna, que surge em 1997, no Hospital Psiquiátrico de Jurujuba, na cidade fluminense de Niterói. A criação do grupo foi motivada pelo interesse da psicopedagoga Cláudia Simone (4) que na época fazia estágio na instituição e, já imersa nas mudanças no tipo de assistência oferecida, iniciou um grupo de teatro que anos mais tarde seria integrado ao Centro de Teatro do Oprimido (CTO).

Nesses quinze anos de existência, o Pirei na Cenna construiu uma trajetória sólida, onde contabiliza mais de 800 apresentaçôes, público total de cerca de 11 mil pessoas e peças encenadas em 12 estados brasileiros. Atualmente o grupo é composto por sete integrantes, sendo seis usuários, um familiar e Alessandro Conceição, que é da equipe do CTO e o responsável por desenvolver a metodologia do Teatro do Oprimido com o grupo; mas mais de cem pessoas (entre usuários, familiares, profissionais da área da saúde e simpatizantes da Luta Antimanicomial) já passaram pelo grupo.

A matéria-prima das peças do Pirei na Cenna são as histórias vividas pelos seus integrantes. Contudo, falar de questóes pessoais nem sempre é muito fácil, ainda mais se o que é contado tem a ver com problemas ligados à saúde mental. Além da dificuldade de se entrar numa área íntima se tocará em questôes ainda cobertas por preconceitos e falta de conhecimento. Porém, o que os usuários do Pirei na Cenna vêm aprendendo é que o silêncio acaba não resolvendo a angústia interna e nem ajuda a acabar com o preconceito, que não raramente acaba por gerar mais angústias. Assim, a força do teatro com seu poder transformador é essencial, como aponta Julian Boal:

Ao fazer teatro, os oprimidos recuperam intelectual e fisicamente a possibilidade
que lhes é negada de produzirem suas próprias representaçóes. Escapam, pelo me-
nos em parte, da identidade imposta pelo outro, o opressor. É uma recuperação e,
também, necessariamente, uma pesquisa, uma investigação. A construção de uma
representação própria passa necessariamente pelo desencadeamento de uma crise
das representaçóes dominantes (BOAL, 2010, p.75).

Deste modo, o presente trabalho optou por analisar os textos de duas peças teatrais do Pirei na Cenna, com o intuito de observar em que medida o trabalho que o grupo desenvolve está consoante com a proposta das 
Epistemologias do Sul e se conseguem promover entre seus integrantes e com a plateia um espaço para a comunicação cultural. Os textos escolhidos foram: 'É melhor prevenir que remédio dar', produzido no período de 2002-2003, que apresenta a questão da sexualidade na vida de usuários dos serviços de saúde mental, discutindo também a prevenção das DSTs e AIDS; e "Doidinhos por trabalho", criada no período de 2007/2008, que promove o debate sobre o desejo dos usuários voltar a trabalhar formalmente e as dificuldades de se encontrar um emprego que aceite pacientes psiquiátricos.

\section{História de um e muitas vezes de todos}

Ao apresentar assuntos que foram vividos, a partir do ponto de vista de quem sofre os efeitos (internos e externos) de ter sido diagnosticado com transtorno mental, o que se percebe é que as questôes trazidas são bastante próximas ao que passa qualquer pessoa com prontuário psiquiátrico ou não. Namoro, trabalho, violência doméstica e discriminação sexual são alguns dos temas que aparecem nas peças do Pirei na Cenna e muitas vezes de um jeito que qualquer pessoa se identificaria. Como pode ser percebido no diálogo do primeiro dia de trabalho de Serverino na casa da Dona Giselda, no trecho da peça "Doidinhos para trabalhar":

SERVERINO - Já sim, senhora. Eu já estou até terminando. O sr. Bráz me informou que eu tenho que arrumar e lavar.

DONA GISELDA - Isso mesmo, lavar, arrumar, passar, cozinhar, passar pano no chão, limpar os vidros da janela, cortar a grama, limpar a piscina, lavar louça, lavar roupa, tirar o cocô da minha cachorrinha e de vez em quando... (DONA GISELDA ALISA O CORPO DE BRAZ COMO SE FOSSE ACARICIÁLO)...cortar o cabelo do Bráz.

SERVERINO - Tudo isso por um salário?

DONA GISELDA - É pegar ou largar.

SERVERINO - Eu pego.

Cabe destacar que nesse momento os patrôes de Serverino ainda não sabiam que ele estava recém-saído de uma instituição psiquiátrica e que um dos motivos pelo qual Serverino aceitou a 'oferta' não poderia ser mais comum a qualquer indivíduo oriundo de uma sociedade capitalista:

SERVERINO (FESTEJANDO) - Oba. Agora vou poder comprar meu fogão em 10 vezes nas Casas Vazias, meu sofá em 36 vezes nas Casas Vazias.

O que essas duas passagens fornecem como leitura é a exploração do trabalho a que muitos empregados domésticos sofrem independente do estado psíquico em que se encontrem. Além disso, a vontade de ter dinheiro para poder se tornar um consumidor ativo também não é exclusivo de usuários dos serviços de saúde mental.

Outros exemplos de situaçóes conflituosas que podem acontecer com qualquer pessoa, podem ser percebidos nas duas passagens colhidas da peça "É melhor prevenir que remédio dar". Na primeira, apresenta-se a discriminação 
sexual em relação à mulher que, como a peça mostra pode começar bem cedo (os personagens principais têm entre 10 e 13 anos), e a violência física, onde só porque um se sente mais forte que o outro pode então fazer valer sua vontade.

ZÉ DA LATA (debochado) - Nóia saia pra lá, vai brincar em outro lugar. Eu sou menino e tenho mais direito.

DALUA (olhando para Nóia) - Que isso, não fala assim com a menina.

ZÉ DA LATA (agressivo) - Tá defendendo sua namoradinha, é? Deixa que eu resolvo isso. (DÁ UM EMPURRÃO EM DALUA)

A segunda passagem aborda um assunto que já foi tema de vários programas de TV e matérias jornalísticas, principalmente quando o foco é relação sexual entre adolescentes: a recusa do homem em usar preservativo masculino.

DALUA (delirante) - Mirta? (SORRI PARA ELA) Vamos fazer o que você me prometeu. (PARTE EM DIREÇÃO A MIRETA QUERENDO TOCÁ-LA)

MIRTA (sedutora e assertiva) - Calma, calma, calma. Olha o que eu trouxe para gente. (MOSTRA A CAMISINHA)

DALUA (meigo) - Não com camisinha não... (MOSTRA O PÊNIS, COM DIFICULDADES DE EREÇÃO)

MIRTA (continuando) - Um beijo bem dado acende um foguinho... carinho também dá tesão. (MOSTRA A CAMISINHA NOVAMENTE PARA DALUA, QUE JOGA NO CHÃO)

DALUA (raivoso) - Não Mirta de camisinha não dá. (MOSTRA NOVAMENTE O PÊNIS COM DIFICULDADE DE EREÇÃO)

MIRTA (insistente) - A gente tem que se proteger e usar camisinha sempre!!!! Ela evita a AIDS, as DSTs e a gravidez indesejada.

DALUA (raivoso) - Mirta eu sou limpinho. É pegar ou lagar, tem um monte de mulher por aí querendo.

Tanto no trecho da brincadeira quanto no do uso do preservativo, a força maior que apresenta os diálogos não é o fato de alguns dos personagens serem usuários, mas sim a possibilidade de também trazerem à tona tabus sociais. Mesmo sem perder de vista que a história encenada foi também vivida por um paciente psiquiátrico, o que acontece é um processo de identificação, no qual é possível que, na plateia, durante uma apresentação, uma pessoa que também trabalhe em casa de família ou uma mulher que já praticou sexo sem proteção reconheça ali um pedaço de sua história.

Se questóes como as destacadas nas passagens anteriores já demonstram ser um grande problema para as pessoas tentarem resolver, ficam ainda pior quando acrescidas do ingrediente 'transtorno mental', pois vem junto a uma série de outros preconceitos ligados à condição do usuário.

No caso, por exemplo, do trecho selecionado abaixo da peça "Doidinhos para trabalhar", quando a patroa descobre que Serverino é paciente psiquiátrico, todo esforço e dedicação demonstrados com o serviço bem feito e o fato deles terem desenvolvido uma boa relação são postos de lado e o Serverino é resumido à imagem estigmatizada da loucura, cunhada ao longo da história. 
DONA GISELDA - Bráz, amanhã mesmo você vai mandar esse maluco embora. Quero esse doido bem longe da minha casa. Como você pôde contratar um maluco, hein, Braz?.

SR BRÁZ - Giselda, minha querida, não seja injusta. Como eu ia saber que o coitado faz tratamento. Além do mais a casa nunca esteve táo cheirosa, arrumada, organizada, nunca comemos tâo bem quanto agora. O Serverino cozinha muito bem. Eu não vou mandar ninguém embora.

DONA GISELDA - Mas, Bráz, ele é maluco. Pode surtar a qualquer momento e quebrar minha casa inteira. Pode quebrar meus cristais. Pode nos agredir. Pode botar fogo na nossa casa.

Assim como ocorre na questáo do trabalho, o tema da sexualidade ganha outra gravidade quando se tem como protagonista uma usuária. Junto às questóes ligadas ao preconceito com o paciente psiquiátrico, ela é interpelada por toda uma sorte de discriminaçóes sociais dirigidas à mulher (louca ou não). O que o trecho abaixo da peça "É melhor prevenir do que remédio dar" demonstra é que, por mais que ela expresse no corpo (com a menstruaçáo, por exemplo) e na fala (com seu desejo de namorar) que o diagnóstico de transtorno mental que recebeu não a limita como mulher, ela é enquadrada na imagem talhada da louca, na qual tem a mente confusa e o corpo 'morto'.

NÓIA (choramingando, passa a mão na barriga e sente dores) - Mãe, mãe me acode, mãe eu me machuquei... mãe!!!! (SUSPENDE A SAIA E DENTRO DA FLOR SAI UMA TIRA DE PANO VERMELHO SIGNIFICANDO A MENSTRUAÇAO DA JOVEM)

DONA ESTRESSADÔRA (olhando em direção ao sangue, com nojo) - Que escândalo é esse. Isso é normal, acontece quando você fica mocinha. Não pode lavar a cabeça. Não pode tomar banho frio. Não pode andar descalça. Não, não, não (FALA AGORA SEM SAIR SOM. NÓIA FICA PARADA OLHANDO PARA ELA E ABISMADA COM TANTOS NÁOS)... E fique longe dos homens.

NÓIA (sonhando vê a imagem do Dalua e ouve as batidas de um coração) Por que mãe? Eu quero namorar.

DONA ESTRESSODÔRA (espantada) - Filha você é maluca. Não pode namorar, não vai casar, quer ter filho maluco?

NÓIA (aliviada) - Eu uso camisinha.

DONA ESTRESSADÔRA (exprime seu espanto) - Onde você aprendeu isso? Você tem é que cuidar da casa.

As duas últimas passagens ajudam a perceber a força das identidades criadas ao longo da história na qual, como aponta Pesavento:

As representaçôes construídas sobre o mundo não só se colocam no lugar deste mundo, como fazem com que os homens percebam a realidade e pautem a sua existência. São matrizes gerados de condutas e práticas sociais, dotadas de força integradora e coesiva, bem como explicativa do real. Indivíduos e grupos dão sentido ao mundo por meio das representaçôes que constroem sobre a realidade (PESAVENTO, 2003, p. 39).

Por isso a relevância de grupos que, como o Pirei na Cenna, ao deixar 
visíveis para a sociedade as marcas de diferenças que possuem em relação à identidade fixa que lhes fizeram 'vestir' e, a todo momento, é 'jogada na cara', conseguem dar a largada para o processo de tradução, negociando as diferenças culturais.

Isso porque uma das práticas da metodologia do Teatro do Oprimido mais utilizada pelo Pirei na Cenna durante as apresentaçôes é o Teatro-fórum, na qual a peça chega em um determinado ponto onde o protagonista (o oprimido) se encontra sem possibilidade para sair da situação de opressão encenada. Nesse momento, pessoas da plateia são convidadas a integrar a peça, ocupando o lugar do protagonista e apresentando teatralmente uma alternativa para tirar o oprimido da situação em que se encontra.

Tal prática é extremamente rica no que diz respeito ao diálogo, ao processo de comunicação cultural, primeiro porque o próprio texto da peça já póem em xeque os estigmas e preconceitos que muitas pessoas do público ainda podem carregar (como o 'louco é incapaz, náo consegue viver em sociedade' etc.) fazendo com que repensem as representaçôes sociais existentes. Em segundo, ao convidar a plateia para tomar o lugar do oprimido, abre-se espaço claro de negociação, pois muitas vezes quem assume o papel do protagonista não é um usuário dos serviços de saúde mental, mas ele propóe uma alternativa para ele, que pode ser ou não eficaz e isso se descobre também na hora, pois a plateia novamente é convidada a responder se a alternativa proposta conseguiu ou não tirar o oprimido do lugar da opressão. Durante o teatro-fórum, o que está em jogo não é se há um saber mais especializado ou mais 'verdadeiro' que o outro, mas sim um espaço de negociaçáo, de troca para juntos tentar chegar a um caminho ou vários - até porque não há resposta certa, mas possibilidades.

Além disso, as peças desenvolvidas pelo Pirei na Cenna também são essenciais para que não caiam no esquecimento práticas e condutas assistenciais ocorridas no passado - que se afastavam do tratamento e funcionavam mais como açôes punitivas (e talvez até de tortura), como o uso do eletrochoque mas que ainda podem existir ou serem retomadas no futuro. Como pode ser observado na passagem abaixo da peça "É melhor prevenir do que remédio dar":

TERAPEUTA (surpresa, fala com o enfermeiro) - O que está acontecendo aqui?

ENFERMEIRO (com humor sinistro) - O paciente tá em crise, fazendo bobagem. Vou dar um sossega-leão.

TERAPEUTA (com firmeza) - Que bobagem?

NÓIA (aliviada) - Namorando.

ENFERMEIRO (com raiva) - Eu sei muito bem o que eles precisam. Você está duvidando da minha experiência?

TERAPEUTA (nervosa) - Não, é que... eu não concordo com sua forma de tratamento.

ENFERMEIRO (com fúria) - Pouco me interessa se você concorda ou não. Vamos logo com isso. (A TERAPEUTA SEGURA A INJEÇÃO PROCURANDO ACALMAR O ENFERMEIRO) 
DALUA - Me escuta, me escuta!!!!

TERAPEUTA (em desespero) - Escuta eles!

ENFERMEIRO (com mais raiva) - Maluco a gente não escuta. Maluco a gente aplica.

Ao trazer para a discussáo muitos dos abusos sofridos dentro das instituiçôes psiquiátricas, consegue-se manter sempre frescos na memória da sociedade os motivos que originaram os Movimentos de Luta Antimanicomial, entre eles a luta por melhores condiçóes de tratamento e, com isso, afastam o risco destas práticas perderem a carga do horror que causaram e voltarem como uma 'nova opção' assistencial. Vivem assim numa negociação contínua de identidades culturais.

\section{Apontamentos conclusivos}

O que este artigo procurou mostrar foi que, por meio do trabalho realizado no Grupo de Teatro do Oprimido Pirei na Cenna, os usuários dos serviços de saúde mental conseguem entrar no cabo-de-força das construçóes das identidades sociais, elaborando suas próprias narrativas e construindo, desta forma, uma outra representação do 'louco' e da 'loucura'.

O que o Grupo de Teatro do Oprimido Pirei na Cenna faz quando monta e apresenta uma peça é justamente abalar as estruturas das identidades historicamente forjadas. Para isso, no momento em que os usuários narram suas histórias a partir de suas visóes de mundo, mostram como as representaçóes sociais existentes são incompletas - pois não dáo conta de representar a pluralidade das identidades, a diversidade cultural existente - e contribuem para a revisão e formação de outras identidades. Assim, pode-se compreender as açóes do Pirei na Cenna como alinhadas ao conceito de Sousa Santos de Epistemologias do Sul, o qual busca a "recuperação dos saberes e práticas dos grupos sociais que, por via do capitalismo e do colonialismo, foram histórica e sociologicamente postos na posição de serem tão só objecto ou matéria-prima dos saberes dominantes, considerados os únicos válidos" (SOUSA SOUSA, 2008, p.11).

O alinhamento do Pirei na Cenna com esta perspectiva faz com que o conteúdo de suas peças seja reconhecido como "história de exploração" e "estratégias de resistência" (BHABHA, 1998, p.26). Nesse sentido, a escolha pelo teatro e pela metodologia do Teatro do Oprimido, como ferramentas para amplificar suas próprias narrativas, foi fundamental, uma vez que, como destaca Cecília Boal:

$\mathrm{O}$ ato teatral supóe a criação de uma linguagem e de um sistema de relaçôes simbólicas no seio de um grupo: ele mobiliza o mundo subterrâneo, colocando em movimento a atividade fantasmática através do corpo e da verbalização, é o seu próprio mundo interno que o ator coloca em cena, dando-lhe forma no espaço e no tempo através da relação com o outro (BOAL, 2010, p. 6-7).

É a partir da abertura desse espaço de mediação (relação com o outro) que o teatro abre, primeiro entre os integrantes e expandindo no contato com a plateia, que se dá início ao processo de tradução das identidades, fazendo ver 
o quanto as definições de identidades culturais são insuficientes para abarcar a gama existente de diversidade cultural.

Mas independente desse encontro gerar um consenso ou não sobre as identidades, o saldo positivo que fica é que as vozes das minorias, como as dos usuários dos serviços de saúde mental, ganharam volume e força para narrar suas próprias histórias. E como Homi Bhabha sugere "agora não há razão para crer que tais marcas de diferença não possam inscrever uma 'história' do povo" (BHABHA, 1998, p.222) 


\section{Referências Bibliográficas}

AMARANTE, Paulo. Reforma Psiquiátrica e Epistemologia. Cad. Bras. Saúde Mental, Vol 1, no1, jan-abr. 2009. Disponível em: http:// periodicos.incubadora.ufsc.br/index.php/cbsm/issue/view/316. Acesso em 4 fev. 2013.

ASSIS, Machado de. O Alienista. In: Obra Completa. Rio de Janeiro:Nova Aguilar, 1994. v. II. Disponível em: http://www.dominiopublico.gov.br/pesquisa/DetalheObraForm.do?select_action $=\& \mathrm{Co}_{-}$ obra=1939. Acessado em 04 fev. 2013.

BHABHA. Homi K. O local da cultura. Belo Horizonte: Editora UFMG, 1998.

BOAL, Augusto. O teatro como arte marcial. Rio de Janeiro: Editora Garamond, 2000.

BOAL, Augusto. A Estética do Oprimido. Rio de Janeiro: Editora Funart, 2008.

BOAL, Cecília. Um teatro subjuntivo. In: Metaxis: informativo do Centro do Teatro do Oprimido, CTO-Rio. Rio de Janeiro: Máster Print, 2010. p 6-9.

BOAL, Julian. Teatro do Oprimido em Eaubonne. In: Metaxis: informativo do Centro do Teatro do Oprimido, CTO-Rio. Rio de Janeiro: Máster Print, 2010. p 75-77.

HALL, Stuart. Da Diáspora: identidades e mediaçôes culturais. Belo Horizonte: Editora UFMG, 2008.

PEREIRA. Carlos Alberto Messeder. O que é contracultura. São Paulo: Editora Brasiliense. 1986.

PESAVENTO. Sandra Jatahy. História \& História Cultural. Coleção Histórias \& Reflexões. Belo Horizonte: Editora Autêntica. 2003 
OLIVEIRA, Alice Guimarães Bottaro de \& ALESSI, Neiry Primo. Cidadania: instrumento e finalidade do processo de trabalho na reforma psiquiátrica. Ciência \& Saúde Coletiva, 10(1):191-203, 2005. Disponível em: http://www.scielo.br/pdf/csc/v10n1/a20v10n1.pdf. Acesso em 04 fev. 2013.

.1

\section{Notas}

(1) A historiadora conceitua o imaginário como "um sistema de ideias e imagens de representação coletiva que os homens, em todas as épocas, construíram para si, dando sentido ao mundo" (PESAVENTO, 2003, p.43).

(2) Para Homi Bhabha tradução é "a natureza performativa da comunicação cultural. É antes a linguagem in actu (enunciação, posicionalidade) do que a linguagem in situ (énounce, ou proposicionalidade). E o signo da tradução conta, ou 'canta', continuamente os diferentes tempos e espaços entre a autoridade cultural e suas práticas performativas." (BHABHA, 1998, p. 313)

(3) Informações sobre o Teatro do Oprimido podem ser encontradas no sítio www. ctorio.org.br. Acesso em: inserir data.

(4) Claudia Simone foi convidada em 2003, por Augusto Boal, a fazer parte do Teatro do Oprimido e atualmente desenvolve a metodologia na França. 